\title{
Clinical-psychological analysis of non-psychotic disorders of former members of the SMT program and its impact to motivation of participation in medical rehabilitation program Grebenyuk A. ${ }^{1}$, Nosovtsov A. ${ }^{2}$, Brovko K. ${ }^{3}$ \\ Непсихотические психические расстройства у бывших участников программы ЗПТ и их влияние на мотивацию к прохождению медицинской реабилитации Гребенюк А. А. ${ }^{1}$, Носовцов А. Е. ${ }^{2}$, Бровко К. А. ${ }^{3}$
}

\author{
${ }^{I}$ Гребенюк Анатолий Анатольевич / Grebenyuk Anatolij - кандидат психологических наук, \\ врач-психотерапевт, врач психиатр-нарколог; \\ ${ }^{2}$ Носовиов Андрей Евгеньевич / Nosovtsov Andrey - медицинский психолог; \\ ${ }^{3}$ Бровко Кирилл Анатольевич / Brovko Kirill - медицинский психолог, \\ дневной стационар, \\ Государственное бюджетное учреждение здравоохранения Республики Крым \\ Крымский научно-практический центр наркологии, г. Симферополь
}

\begin{abstract}
Аннотация: по результатам клинико-психологического анализа установлены значимые корреляционные связи между признаками аддиктивной деформачии личности и расстройствами невротического спектра у пациентов, ранее получавших заместительную терапию метадоном/бупренорфином. Описана рабочая мотивационная модель поведения пациентов, бывщих участников ЗПТ, объясняющая механизм образования у них симптомов невротического спектра и их влияние на отночение к медицинкой реабилитации. Предложен когнитивно-смысловой подход при проведении психотерапии, в котором используются методы когнитивно-поведенческой терапии и смыслотехники.

Abstract: according to the results of clinical-psychological analysis established significant correlations between deformation features addictive personality disorders and neurotic spectrum among patients previously treated with methadone/buprenorphine. We describe the working model of the motivational behavior of patients, former members of the SMT, that explains the mechanism of formation their neurotic symptoms of the spectrum and their impact on attitudes towards rehabilitation. Offer a cognitive-semantic (cognitive-sense) approach during therapy, which uses methods of cognitive-behavioral therapy and semantic (meaning) techniques.
\end{abstract}

Ключевые слова: качество жизни, заместительная поддерживающая терапия, метадон, бупренорфин, крейвинг, когнитивно-поведенческая терапия, когнитивно-смысловая терапия, КСАкТ, смыслотехника. Keywords: quality of life, substitution maintenance therapy, methadone, buprenorphine, craving, cognitivebehavioral therapy, cognitive-sense therapy, CSAcT, semantic (meaning) techniques.

\section{Введение}

После прекращения 20 мая 2014 года заместительной поддерживающей терапии (ЗПТ) в Республике Крым [7], особую актуальность приобрела медицинская реабилитация пациентов, на протяжении многих лет получавших препараты метадон и бупренорфин [1, 6]. Как показали наши исследования [2], через 7-9 месяцев после последнего приёма замещающих опиоидных препаратов у бывших участников ЗПТ сохранялось выраженное влечение к метадону/бупренорфину и многочисленные непсихотические психические расстройства, имманентные злоупотреблению опиоидами, которые существенно ухудшали качество их жизни. В структуре выявленной патологии у данной категории пациентов превалировала пентада следующих симптомов: отвращение к трезвости; выраженное аддиктивное влечение к метадону/бупренорфину; амотивационный синдром (вплоть до амотивационного коллапса); социофобия и агрипнический синдром. На этом фоне в своём большинстве (68 \%) пациенты проявляли выраженное негативное отношение к любым видам медицинской помощи, кроме заместительной терапии опиоидными анальгетиками. Данное поведение наиболее активно демонстрировали те из них, кто в период получения терапии замещающими препаратами систематически самовольно употреблял различные психоактивные вещества с целью усиления состояния эйфории.

Решение проблемы повышения интереса пациентов к прохождению восстановительной терапии потребовало изучения влияния имевшихся у них непсихотических психических расстройств, имманентных злоупотреблению опиоидами - на мотивацию к медицинской реабилитации.

Материалы и методы исследования

Всего было обследовано 115 бывших участников программы ЗПТ в Республике Крым (сайт г. Симферополя).

Диагноз: F11.2 Синдром зависимости, вызванный употреблением опиоидов.

Из них: мужчин - 88, женщин -27.

Средний возраст обследованных составляет $40( \pm 8,6)$ лет. 

22.

В период прохождения ЗПТ получали метадон («Метадол») - 93 человека, бупренорфин («Эднок») -

Средний стаж пребывания на ЗПТ составляет $3,6( \pm 2,02)$ года.

Последний приём замещающих опиоидных препаратов - от 7 до 9 месяцев назад. Все пациенты ранее прошли детоксикацию в условиях круглосуточного и дневного стационаров и находились под наблюдением у участковых врачей психиатров-наркологов.

Из общего числа обследованных 56 человек (48,6 \%) страдают опасными заболеваниями (ВИЧ, вирусные гепатиты, туберкулёз): ВИЧ - 5 человек, вирусные гепатиты -20 , туберкулёз - 3, ВИЧ + вирусный гепатит - 13, ВИЧ + туберкулёз - 4, вирусный гепатит + туберкулёз - 2 .

Согласно анамнестическим данным, 69 человек $(60 \%)$ на фоне приёма замещающих препаратов систематически употребляли различные наркотические вещества и психофармакологические препараты с целью достижения состояния эйфории.

В период обследования употребление наркотиков категорически отрицали $15 \%$ обследованных пациентов. Указали на ежедневное употребление «уличных» опиатов 43 \%; употребление с частотой 1-4 раза в месяц - $42 \%$. При этом сдать анализ для токсикохимического исследования дали согласие $33 \%$ пациентов (35 чел.). Из их числа наркотики не обнаружены у $11 \%$ (4 чел.). У остальных 31 обследованных обнаружены различные психоактивные вещества: опиаты (41\%), эфедрин-содержащие вещества (28 \%), каннабиноиды (15\%), барбитураты (5\%). У 27 \% из них - несколько видов наркотиков (в основном опиаты и эфедрин-содержащие вещества).

Социальный статус паџиентов: не работают - $77 \%$. Имели судимости и ранее отбывали наказание в местах лишения свободы $72,1 \%$, в том числе 50,4 \% - 2 и более раз. Женаты (замужем) - $29 \%$, постоянное сожительство - $22 \%$, одиноки - $49 \%$. У $19 \%$ пациентов их постоянный партнёр страдает зависимостью от наркотиков (находится в ремиссии - $3 \%$, употребляет наркотики - $16 \%$ ).

У 105 пациентов (91 \% от общего количества обследованных) были выявлены следующие непсихотические психические расстройства, имманентные злоупотреблению опиоидами:

Расстройства невротического спектра:

○ тревожно-ипохондрические - $18 \%$,

○ фобические нарушения - $23 \%$ (кроме социофобии),

○ социофобия $-73 \%$,

○ нарушения сна $-73 \%$,

○ стойкие опасения тягостного абстинентного психофизического дискомфорта (фобия отмены) $72 \%$

Признаки аддиктивной деформации личности:

○ снижение порогов восприятия психогенных раздражителей, следствием которого является повышенная психическая уязвимость - $77 \%$;

○ резкое снижение переносимости психофизического дискомфорта - $73 \%$;

○ поведение, направленное на получение удовольствий от психоактивных веществ (аттрактивный таксис) $-72 \%$;

○ мотивационный коллапс $-72 \%$;

○ стойкое стремление к модуляции собственного психофизического состояния с помощью психоактивных веществ - $67 \%$.

У всех обследованных определялась апатическая депрессия (73\% - депрессивный эпизод средней степени; $27 \%$ - депрессивный эпизод лёгкой степени). При этом так же отмечалось снижение аппетита, связанное с ангедонией.

Изучение значимых связей между признаками аддиктивной деформации личности и расстройствами невротического спектра осуществлялось при помощи коэффициента корреляции Пирсона. После этого проводился клинико-психологический анализ влияния выявленных зависимостей на мотивацию к прохождению медицинской реабилитации.

Результаты

Проведённый математический анализ выявил следующие значимые корреляционные связи между признаками аддиктивной деформации личности и расстройствами невротического спектра:

1. На уровне 0.01 (для 2-х сторон):

- между регулярным самовольным употреблением пациентами различных психоактивных веществ в период приёма замещающих препаратов и аттрактивным таксисом и неприятием других видов помощи кроме «лечения» наркотическими анальгетиками;

- $\quad$ между нарушениями сна и стойким стремлением к модуляции собственного психофизического состояния с помощью ПАВ, психофизическим дискомфортом, фобией отмены, аттрактивным таксисом, мотивационным коллапсом, апатической депрессией, социофобией, снижением порогов восприятия психогенных раздражителей, неприятием других видов помощи кроме «лечения» наркотическими анальгетиками; 
- между фобией отмены и стойким стремлением к модуляции собственного психофизического состояния с помощью ПАВ, аттрактивным таксисом, мотивационным коллапсом, апатической депрессией, социофобией, неприятием других видов помощи кроме «лечения» наркотическими анальгетиками, психофизическим дискомфортом, нарушением сна, снижением порогов восприятия психогенных раздражителей;

- между фобическими нарушениями и тревожно-ипохондрическими нарушениями, мотивационным коллапсом, апатической депрессией, социофобией, неприятием других видов помощи кроме «лечения» наркотическими анальгетиками.

На уровне 0.05 (для 2-х сторон):

- между регулярным самовольным употреблением пациентами различных психоактивных веществ в период приёма замещающих препаратов и: нарушениями сна, социофобией, фобией отмены, мотивационным коллапсом, апатической депрессией, стремлением к модуляции психофизического состояния с помощью ПАВ.

Анализ и обсуждение полученных данных

Выявленная значимая линейная зависимость между регулярным самовольным употреблением пациентами ПАВ с целью усиления эйфоризирующего действия замещающих препаратов и симптомами аттрактивного таксиса показывает, что приём замещающих препаратов не снижал потребность пациентов в достижении состоянии эйфории. Пациенты объясняли данную связь тем, что для них метадон/бупренорфин выступал не только препаратом, предупреждающим синдром отмены, но и средством подготовки организма к последующей интоксикации (то есть «вводной» наркотизации). При этом индивидуальные «пристрастия» в приёме тех или иных ПАВ были связаны с их желанием достичь определённых состояний опьянения. Например, сочетание бупренорфина с небольшими дозами алкоголя позволяло части из них достичь эйфории, характерной при употреблении ацетилированного опия. Сочетание «Метадола» с бензодиазепинами или димедролом - опьянения, похожего на эффект от употребления больших доз трамадола или «уличных» опиатов и так далее. Сформированная установка на приём лекарственных препаратов с целью «вводной наркотизации» значительно осложняла понимание пациентами сути медицинской реабилитации и снижала мотивацию на её прохождение.

Помимо этого, пациентами отмечалось, что в период приёма замещающих препаратов у них также возникало состояние «автоматического» употребления ПАВ без желания получения удовольствия. Оно инициировалось доступностью вещества и реализовывалось как результат остро возникшего желания без размышления и, по нашему мнению, являлось проявлением крейвинга.

Изучение психологической природы корреляционной связи систематического употребления ПАВ на фоне приёма замещающих опиоидных препаратов с мотивационным коллапсом и апатической депрессией показало, что в её основе лежал разрыв привычного шаблона достижения больными состояния опьянения. Так, все пациенты отмечали своеобразную выраженную «утреннюю растерянность», обусловленную выраженной тягой к «Метадолу»/«Эдноку» и невозможностью его получения. Данное переживание полностью заполняло сознание больных, в результате чего они пребывали, по меткому выражению одного из них, в состоянии «тупой потерянности». Те из пациентов, кто имел возможность употребить «уличные» наркотики, отмечали снижение удовольствия от их приёма. С их слов, им не хватало ощущения «привычной» подготовки организма замещающим препаратом к последующей интоксикации другим ПАВ. В свою очередь, открытие забытых ощущений собственного тела, которые были «приглушены» замещающими препаратами на протяжении многих лет, воспринималось пациентами как проявление психофизического дискомфорта вне интоксикации и способствовало нарушению у них засыпания. Недостаточное осмысление возникшей проблемной ситуации и неверная интерпретация имевшихся патологических симптомов в значительной мере ослабляли мотивацию пациентов к прохождению медицинской реабилитации, что требовало оказания им когнитивно-ориентированной психотерапевтической помощи.

В процессе работы с пациентами, бывшими участниками ЗПТ, мы обратили внимание на проявление в их поведении определённых компульсивных поведенческих стереотипов, отражавших привычную схему взаимодействия с медицинским персоналом, который ранее был обязан выдавать замещающие опиоидные препараты. В частности, они проявляли особую навязчивость в своих просьбах-требованиях, выдать/выписать им метадон/бупренорфин, трамадол, релланиум - препараты, которые они получали в период пребывания в программе ЗПТ. При этом, в отличие от других пациентов, зависимых от наркотиков, это поведение не столько преследовало цель действительно получить данные препараты, сколько реализовать потребность в осуществлении определённого порядка действий. Следует отметить, что бывшие участники ЗПТ в течение 7-9 месяцев до проводимого нами обследования были многократно проинформированы о порядке оказания и характере оказываемой амбулаторной и стационарной наркологической помощи; всем им было известно, что препараты метадон и бупренорфин в лечении более не используются; что для назначения трамадола и релланиума необходимы соответствующие показания и прочее, однако они при обращении к врачу невольно начинали демонстрировать описанную 
выше форму поведения. Выявленные компульсивные поведенческие стереотипы мы объясняем «сенситизацией к влечению» (incentive-sensitization) [5] и включением медицинских работников в семантическое пространство образа крейвинга. На протяжении длительного времени для пациентов удовлетворение тяги к опиоидам было связано с систематическим приёмом замещающих препаратов. В итоге, условия проведения ЗПТ и участники данного процесса стали выступать оперантами, встреча с которыми автоматически развёртывала закрепившуюся систему психологических, физиологических, поведенческих и других характеристик, характерных для актуализации крейвинга. Встреча с медицинским работником в условиях наркологического учреждения актуализировало у пациентов патологическую потребность в препаратах, которые ассоциировались с ЗПТ, а также стереотипные формы поведения, связанные с их получением. Эти особенности в дальнейшем были нами учтены при организации и проведении с данными пациентами медицинской реабилитации.

Зависимость между фобией отмены и стойким стремлением к модуляции собственного психофизического состояния с помощью ПАВ, аттрактивным таксисом, мотивационным коллапсом, апатической депрессией, социофобией, неприятием других видов помощи кроме «лечения» наркотическими анальгетиками, психофизическим дискомфортом, нарушением сна, снижением порогов восприятия психогенных раздражителей доказывает роль данных симптомов в появлении страхов, связанных с полным отказом от употребления ПАВ. Эта связь проявлялась у пациентов в том, что они даже по истечении длительного срока после прекращения употребления метадона/бупренорфина объясняли себе перечисленные патологические симптомы пролонгированным во времени синдромом отмены замещающих опиоидных препаратов, а потому были ориентированы на получение соответствующей помощи, а не медицинской реабилитации.

Значимая корреляционная связь фобических нарушений с тревожно-ипохондрическими нарушениями, мотивационным коллапсом и апатической депрессией и социофобией на фоне отсутствия значимой корреляционной связи тревожно-ипохондрических нарушений с признаками аддиктивной деформации личности говорит в пользу того, что фобические нарушения, как форма психологической защиты, вероятно, являются характерными для пациентов, имеющих тревожно-мнительные черты личности. В свою очередь, данная зависимость позволяет использовать её при проведении мотивационного консультирования пациентов на прохождение ими медицинской реабилитации.

Выявленная зависимость между регулярным самовольным употреблением пациентами различных психоактивных веществ в период приёма замещающих препаратов и нарушениями сна, социофобией, фобией отмены, мотивационным коллапсом, апатической депрессией, стремлением к модуляции психофизического состояния с помощью ПАВ, по нашему мнению, отражает реакцию субъекта на условия, противоречащие его устойчивому положительному отношению к ПАВ. Прекращение практики ЗПТ поставило пациентов в ситуацию, потребовавшую пересмотра ими своего отношения к наркотикам, а значит, обострило для них страх потери привычного мира. Результатом этой внутренней борьбы выступили разнообразные невротические симптомы. В частности, попытка отложить решение проблемы зависимости от опиоидов и других ПАВ путём ухода в невротические симптомы отражала привычную для них цель получить от нарколога если не наркотические анальгетики, то хотя бы те из психофармакологических средств, которые могли бы вызывать состояние эйфории. Тем самым врачам неуклонно навязывалась ставшая шаблонной для пациентов модель ЗПТ и игнорировались иные возможности восстановления психофизического комфорта без использования наркогенных веществ.

Исходя из полученных результатов, нами была сформирована следующая мотивационная модель поведения пациентов, бывших участников ЗПТ, объясняющая механизм образования непсихотических психических симптомов, имманентных злоупотреблению ПАВ и их влияние на отношение к медицинской реабилитации.

Основу поведенческого предпочтения замещающих опиоидных препаратов и ассоциативно связанных с ними ПАВ составляет крейвинг («тяга»; аддиктивное влечение). Данное состояние обусловлено нарушением механизмов работы дофаминергической системы и проявляется на поведенческом уровне стремлением к употреблению ПАВ без желания получения от них удовольствия [9]. В когнитивном плане образ крейвинга представляет собой семантическое пространство, включающее в себя следы переживаний бывших деятельностей, поведения, физиологических реакций и прочих психических эффектов, проявлявшихся в условиях актуализации тяги к замещающим опиоидным препаратам и их ассоциантам. Фиксируясь в памяти субъекта, этот образ задаёт качественно новое отношение к этим ПАВ как объектам, имеющим устойчивое личностное значение. Выступая семантическим коррелятом крейвинга, данное отношение закрепляется в смысловой сфере в форме диспозиции и начинает проявляться как «аддиктивная» черта личности. Эта новообразованная черта диктует избирательную уязвимость субъекта к ПАВ и определённому роду психогенных воздействий, ассоциированных с его употреблением, при хорошей устойчивости к другим внешним факторам. Задавая «зону» повышенной перцептивной активности в отношении ПАВ и ассоциированных с ними раздражителей (то есть, формируя соответствующую функциональную «настройку» образа мира), 
аддиктивная черта побуждает субъекта активно выискивать социальные ситуации, способствующие её актуализации. При этом личность ориентируется не на получение удовольствия от употребления ПАВ, а на возможность их употребления.

Появление «крейвинг-черты» требует своего погружения в миф, который создаст образ действительности, соответствующий ценностным ожиданиям её носителя. Этот миф должен задавать систему базовых ориентиров, позволяющих представителю конкретной культурной общности твёрдо знать, какие факторы оправдывают его отказ от управления собственным поведением и психическими функциями в ситуациях, связанных с ПАВ.

Мы полагаем, что таким мифом стал миф одержимости крейвингом, сформированный на основе существующего в любом обществе мифа одержимости. Миф, обеспечивающий механизм бегства от социальных требований с обретением определённой степени свободы действий, путём демонстрации утраты способности управлять желаниями, связанными с ПАВ.

Так как каждая составляющая, входящая в семантическое пространство образа крейвинга, может являться своего рода «ключом» к возникновению данного состояния, при встрече с таким оперантом автоматически развёртывается закрепившаяся за ним система психологических, физиологических, поведенческих и др. характеристик, характерных для актуализации состояния. В свою очередь, возведение ПАВ в ранг объекта, устойчиво значимого для личности, сопровождается формированием перцептивных схем, стереотипов движения и семантико-перцептивных универсалий, отражающих влияние стабилизирующих, преградных, отклоняющих и дезорганизующих смысловых установок на течение актуальных деятельностей. В этих условиях актуализация крейвинга проявляется наплывом автоматически возникающих ошибочных концептуализаций (мыслей) и дисфункциональных убеждений (схем). Эти ошибочные концептуализации ложатся в основу многочисленных патологических психических симптомов, имманентных злоупотреблению ПАВ, которые уводят пациента от осознания истинной природы своего наркологического заболевания и оказывают тем самым негативное влияние на мотивацию к восстановительному лечению.

Учитывая то, что в основе крейвинга лежат нейробиологические нарушения, его семантический коррелят будет постоянно нести в себе установки и концептуализации, определяющие поведенческое предпочтение ПАВ. Данные дисфункциональные образования могут быть скорректированы при помощи когнитивноповеденческой терапии, однако полная коррекция патологических мыслей и иррациональных убеждений будет невозможна по причине их постоянного воспроизводства в условиях биологически обусловленной «сенситизации к влечению». В то же время, может быть изменён характер их присутствия в сознании за счёт изменения их смысла для личности.

Опираясь на созданную мотивационную модель поведения пациентов, бывших участников ЗПТ, с целью повышения общей эффективности лечения мы используем разработанную нами краткосрочную, стратегически-партнёрскую, структурированную, симптомо-ориентированную стратегию активизации самоисследования и изменений когнитивных и смысловых структур Я, обуславливающих отказ от управления желаниями, связанными с ПАВ, с подтверждением изменений на поведенческом уровне когнитивно-смысловую антикрейвинговую терапию (КСАкТ) [3].

В операциональном плане $K C A \kappa T$ представляет собой комплекс смыслообразующих технологических воздействий и дидактических приёмов психологической ориентации, идущих от создаваемой ситуации либо производимых малозаметным способом, позволяющих в обход психологических защит клиента побудить его выполнить операции по изменению смысловых и когнитивных схем, нарушающих способность осознавать себя в качестве независимого самостоятельного индивида, который может управлять собственными желаниями, связанными с ПАВ.

В качестве основного терапевтического метода используется модифицирующая дискурсивная практика, которая позволяет терапевту осуществить активную целенаправленную трансляцию смыслов, разрушающих миф одержимости крейвингом. Инициируемый терапевтом семиозис (смысловые трансформации, позволяющие заново организовать субъективное семиотическое пространство пациента, свободное от вдохновляющих активность маркеров ПАВ), постепенно формирует новые ориентиры поведенческих паттернов. Поскольку семиотическое моделирование реальности осуществляется, в том числе, и посредством бессознательного смыслообразования, у пациента не возникает навязчивого ощущения внешнего управления контроля.

Антикрейвинговая модифицирующая дискурсивная практика строится на принципах построения дискурса, лежащих в основе лингвистической психотерапии [4], с использованием различных языковых моделей, получивших распространение в коммуникативной практике искусства авангарда [8] и механизмах смыслотехнического воздействия [5].

Клиническими критериями эффективности КСАкТ выступают формирование приверженности к участию в программе стационарного лечения; появление заинтересованного отношения к выполнению врачебных назначений; заинтересованное согласие пациента на приём блокаторов опиоидных 
рецепторов; заинтересованное участие в групповой и индивидуальной психотерапевтической и психокоррекционной работе.

\section{Выводы}

1. Между признаками аддиктивной деформации личности и расстройствами невротического спектра выявляются значимые корреляционные связи, объясняющие особенности отношения больных к ПАВ и их мотивацию к прохождению медицинской реабилитации.

2. Прекращение практики ЗПТ и жёсткая государственная политика нетерпимости в отношении немедицинского употребления наркотических веществ потребовали от бывших пациентов ЗПТ пересмотра своего отношения к наркотикам, что обострило у них страх потери привычного мира и способствовало появлению разнообразных защитных симптомов невротического спектра.

3. Раскрытие психологического смысла симптомов невротического спектра позволило обозначить феномены, оказывавшие негативное влияние на мотивацию пациентов к прохождению медицинской реабилитации. К их числу были отнесены:

- установка на приём лекарственных препаратов как средство создания благоприятных психофизиологических условий для последующей наркотизации;

- установка на объяснение любых патологических симптомов, имманентных злоупотреблению ПАВ, пролонгированным во времени синдромом отмены;

- компульсивные употребления фармакологических препаратов без желания получения удовольствия, провоцируемое их доступностью;

- недостаточное понимание путей конструктивного выхода из возникшей проблемной ситуации, связанной с прекращением ЗПТ, и ошибочная интерпретация имеющихся патологических симптомов;

- проявление «сенситизации к влечению» в форме компульсивных поведенческих стереотипов, отражавших привычную схему взаимодействия с медицинским персоналом, который был обязан выдавать замещающие опиоидные препараты;

- установка на уход от решения проблемы зависимости от ПАВ путём ухода в невротические симптомы, с целью получения психофармакологических средств с высоким аддиктивным потенциалом.

4. С целью повышения эффективности лечения бывших участников программы ЗПТ предлагается использовать когнитивно-смысловую антикрейвинговую терапию - стратегически-партнёрскую, структурированную, симптомо-ориентированную стратегию активизации самоисследования и изменений когнитивных и смысловых структур Я, обуславливающих внутренний отказ от управления желаниями, связанными с употреблением ПАВ.

\section{Лuтература}

1. Виноградова T. Брюн: Россия сказала реабилитации наркоманов - да, метадону - нет / [Интервью с Е. А. Брюном] // Риановости. 2015. 20 июля. [Электронный pecypc]: URL: http://ria.ru/interview/20110417/365361420.html.

2. Гребенюк А. А. К вопросу качества жизни, связанного со здоровьем, у бывших участников программы заместительной поддерживающей терапии // Наркология. 2016. N 2. С. 45-48.

3. Гребенюк A. А., Носовиов A. E. Теоретико-психологические основы и методика проведения когнитивно-смысловой антикрейвинговой терапии // Проблемы современной науки и образования. 2016. № 17 (59). С. 103-112. doi: 10.20861/2304-2338-2016-59-002.

4. Калина Н. Ф. Лингвистическая психотерапия. - К.: Ваклер, 1999. - 282 с.

5. Леонтьев Д. А. Психология смысла: природа, строение и динамика смысловой реальности. 2-е, испр. изд. - М.: Смысл, 2003.

6. Отлучение наркоманов от метадоновой терапии в Крыму прошло успешно / [Интервью с Т. В. Клименко] // РИА Крым. 2015. 26 июня. [Электронный pecypc]: URL: http://crimea.ria.ru/society/20150626/1100329440.html.

7. Официальное сообщение о закрытии программы ЗПТ в Крыму. МБФ «Міжнародний Альянс 3 ВIЛ/СНIД в Україні» сообщение от 23.05.2014, [Электронный pecypc]: URL: http://motilek.com.ua.

8. Чипизубова М.И. Дискурсивные приемы театра авангарда как разновидность коммуникативного семиозиса: дис. ... канд. филол. наук: 10.02.19 / Чипизубова Марина Ивановна. - Краснодар, 2004. $161 \mathrm{c}$.

9. Robinson T. E., Berridge K. C. The neural basis of drug craving: An incentive-sensitization theory of addiction. Brain Research Reviews. 1993; 18 (3): 247-291. doi: 10.1016/0165-0173(93)90013-p. 